\title{
Tool tests challenge chimpanzees
}

\section{Do apes fail to understand physics, or do we fail to understand them?}

\section{Folk Physics for Apes: The \\ Chimpanzee's Theory of How The World Works \\ by Daniel J. Povinelli \\ Oxford University Press: 2000. 407 pp. \\ $£ 49.50, \$ 85$}

\section{Andrew Whiten}

As discoveries surfaced that chimpanzees can make tools and show self-recognition along with social politicking and cultural variation, the mental gap between us and them appeared to shrink so far that serious proposals were made to extend human-rights legislation to great apes. In some countries special protection is already in place.

Given this Zeitgeist, the results presented by Daniel Povinelli and his colleagues in Folk Physics appear quite shocking. They describe 27 meticulously conducted and previously unpublished experiments designed to assess what chimpanzees really understand about the way their physical world works. Seven young chimpanzees were tested on a dozen different kinds of tool use between the ages of five and ten years. Again and again, these juvenile chimpanzees apparently failed to take into account basic aspects of causality, such as that food will not fall 'up' into a container swung from its usual position so as to lie above the food, or that a hook needs to do more than merely touch its target to be a useful tool.

Povinelli's central conclusion is that there is a major, qualititative difference between the everyday 'folk physics' of humans, who can mentally represent unobservable causal factors such as gravity and force, and the chimpanzee's folk physics, which is limited to perceptually available information. Given the significance of this claim, and that Povinelli's group also studies children, it is surprising that we are not reassured by data showing that young children respond differently to the tasks the chimpanzees were set.

Be that as it may, the experiments follow a sustained logic that is fully and clearly explained. If the conclusions are correct, they have far-reaching implications for both chimpanzees and humans. How seriously should we take these results? There is space here to highlight just two main concerns. One is that the juvenile chimpanzee subjects were separated from their mothers in infancy (usually at birth) and reared as a peer group. How would cognitive performance be affected in human subjects reared in the same way? Were inputs that are crucial for a developing chimpanzee absent? Povinelli's answer is that the juveniles' experiences with a variety of tool-based tasks were in all likelihood richer than those of wild chimpanzees. This

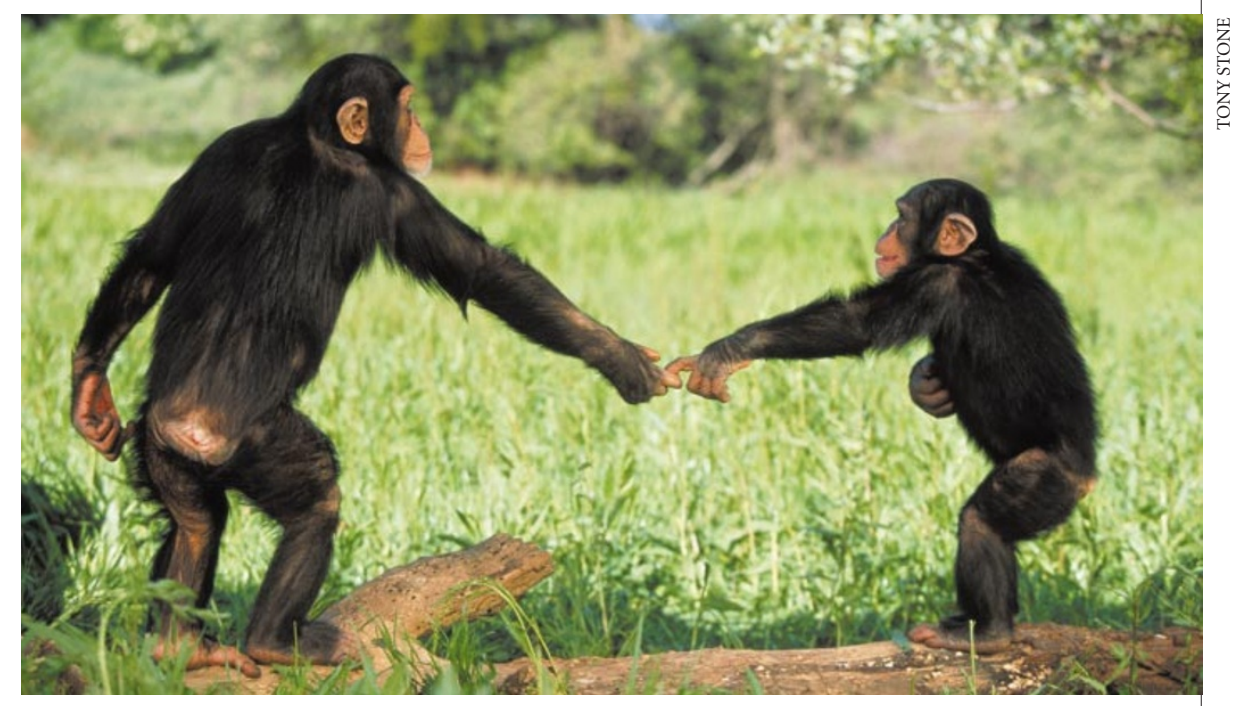

Hang on: we may have overestimated chimpanzees' ability to comprehend how things work.

seems a compelling point. Caution remains, however, if primatologist Tetsuro Matsuzawa of Kyoto University is correct in inferring, from his analysis of how skills develop in the wild, that there is a critical period in infancy that is required for the proper, hierarchical development of competent tool use.

A lengthy opening chapter criticizes the 'argument by analogy' — the (mistaken) assumption that if members of two different species behave in similar ways, the same underlying cognitive processes must be at work. I was not persuaded that such criticism offers a radically new insight. Comparative psychologists already know that any behavioural similarity, on further probing, may turn out to be achieved by different cognitive processes. I am equally unconvinced that a fundamental logical flaw exists here, for it would imply that even the deepest probing could never establish both the differences and the similarities in cognition that comparative psychologists seek to delineate.

Perhaps Povinelli has himself fallen victim to the argument by analogy. He illustrates his critique by quoting his earlier studies, which gave a resounding negative verdict to the question of whether chimpanzees understand 'seeing. This conclusion appears to be based on the analogy that a child failing such tests (understanding the implications of someone covering their eyes) would be unlikely to understand seeing in general. Recently, more natural experiments (involving competition with other chimpanzees over food) were carried out by Brian Hare and his colleagues showing that chimpanzees can and do discriminate important aspects of seeing (and perhaps even the 'knowing' following on from this).
Therefore, we now have to consider that such an analogy does not extend to chimpanzees.

And so to the second major concern. If Povinelli's gigantic prior analysis of chimpanzees' folk psychology can be overturned by an elegant experiment more intuitive for chimpanzees, what of the prospects for the current, equally voluminous onslaught on folk physics? Time will tell. Whatever the answer, this book presents a rigorously documented set of internally consistent results that offer a stalwart challenge for anyone harbouring ambitions to chart the true mentality of chimpanzees.

Andrew Whiten is at the School of Psychology, University of St Andrews, Fife KY16 9JU, UK.

\section{Blazing a trail that led to the Moon}

\section{Shoemaker by Levy: The Man Who Made an Impact \\ by David H. Levy \\ Princeton University Press: 2000. 303 pp.

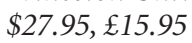 \\ David W. Hughes}

The American astrogeologist Eugene Merle Shoemaker (1928-97) was the sort of scientist that most scientists would be proud to be. Shoemaker worked hard all his life, published profusely, clearly enjoyed himself, and left his mark. He was a fountain of ideas, and a man who was only too happy to share these precious thoughts with his many friends and students. ("I'm a professor," Shoemaker told 


\section{book reviews}

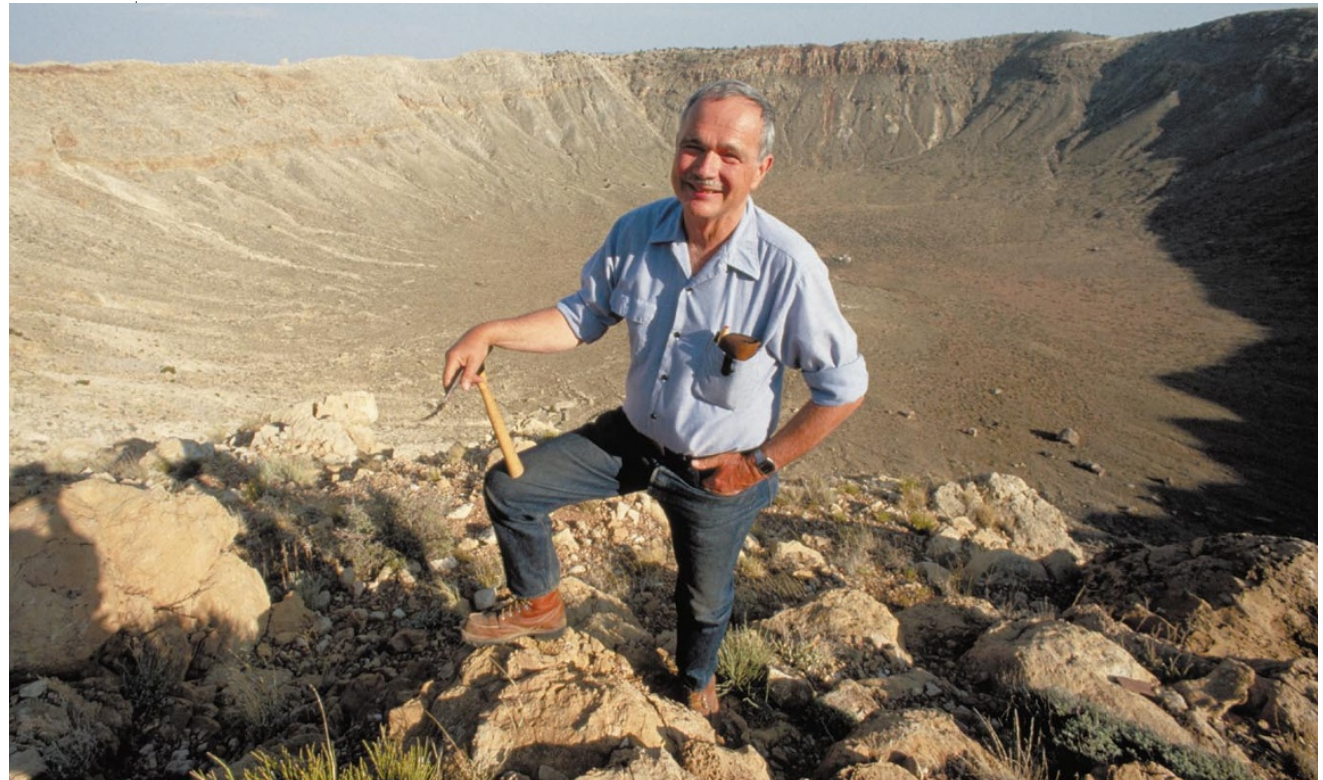

Deep impact: visiting Meteor Crater as a young student set Shoemaker's career on a new course.

one of his grateful colleagues. "My job is to give away ideas.")

Like many Nature readers, he was confronted with the juggling act of modern academia - university duties, research work, grant-proposal writing, data analysis, administration, committee membership all competed for his time. But Shoemaker had a clear view of what he wanted to do, and just did it. Shoemaker was in his early sixties when Levy first met him, but the book under review goes to considerable pains to provide an overview of Shoemaker's early life.

In 1944, aged 16, Shoemaker entered Caltech to study geology. By 1948 he had joined the US Geological Survey and begun his scientific career by specializing in the stratigraphy of the Colorado Plateau and specifically the genesis of its uranium deposits. This was to have been the basis of his Princeton doctoral thesis. But fieldwork in the Rockies had led to a short detour to Meteor Crater on the Arizona-New Mexico border, and the sight of this impact feature was to colour Shoemaker's career from then on.

By 1956, the US government's interest in uranium had moved on to plutonium, and Gene joined a programme called Project MICE. Here, it was hoped, retrievable plutonium would be produced in a Megaton Icecontained Explosion.

In studying this problem, Shoemaker visited some of the artificial craters that had been produced in the United States by small kiloton nuclear explosions. He noticed that the craters bore an uncanny resemblance to Meteor Crater. Gene returned to Arizona and changed his doctoral topic. His new thesis suggested that Meteor Crater, although nestling in a highly volcanic area, was actually produced by the impact of an iron asteroid. He proved this to be true a year later by his discovery of nearby coesite. This high-density quartz only crystallizes out under conditions of very high pressure and temperature that are only naturally obtained during the brief moments of impact.

The similarities between impact craters on Earth and on the Moon, and the United States' blossoming lunar exploration ambitions, led to Gene becoming the founder director of the astrogeology programme in the US Geological Survey. NASA then decided not to set up a separate space geology centre; they used Shoemaker's group instead. Gene desperately wanted to fly to the Moon himself and "bang on it with his own hammer". But in 1963 he fell ill, and was eventually diagnosed as having Addison's disease, caused by a malfunction of the adrenal glands. Fortunately, cortisone treatment was just being introduced. Gene was on cortisone pills for the rest of his life, but his dreams of becoming an Apollo astronaut were scuppered.

Nevertheless, Shoemaker almost singlehandedly put the science into the US Apollo mission. He was closely associated with the crash-landing Project Ranger, and the softlanding Project Surveyor, which showed that the lunar soil would support the weight of a spacecraft and an astronaut. But Shoemaker was worried that NASA was concentrating too much on getting men to the Moon and back, and far too little on what they should do while they were there. People were only useful if they could do what a machine could not - setting up and checking out equipment could be done robotically. Astronauts, according to Shoemaker, should be explorers and field geologists. He considered it a waste of time sending humans into space if they were not trained to expect the scientifically unexpected, and to react positively to it.

By 1969, Gene had fallen out with NASA. He left after the Apollo 13 mission and returned to Caltech to chair the geology department. But he did not enjoy the minutiae of administration, and when he lost interest in a project, he tended to ignore it. He resigned the chair in 1972 and went back to pure research, with the goal of understanding the interrelationship between impacting asteroids and comets and the resulting craters. In 1973, Gene joined Eleanor Helin in setting up the Palomar Planet-Crossing Asteroid Survey, using their 18-inch Schmidt telescope. By 1980, he had been joined by his wife Carolyn, and Eleanor moved to the 48 -inch Schmidt.

The Shoemakers were adept at discovering comets and asteroids. Their 'bag' contained 32 of the former and 1,125 of the latter. This harvest was topped by the astounding discovery of P/Shoemaker-Levy 9 on 24 March 1993. The fragments of this comet pulled apart by tidal forces after approaching Jupiter too closely in July 1992 — hit Jupiter in July 1994.

In June 1984, Gene had returned to his "rock-knocking" fieldwork, spending three months each southern winter in the Australian outback, camping under the stars with his wife, and investigating old impact sites. But on 18 July 1997, he died in a car crash near the border of the Northern Territory and Western Australia.

David Levy joined the Shoemaker Palomar team in July 1989 and quickly became a firm friend and valued colleague. Shoemaker by Levy concentrates on this period, and deals in detail with the media interest engendered by the impact of the fragmented Shoemaker-Levy 9 with Jupiter. Levy writes well, and his pacey style keeps his personal story bubbling along superbly. The book is everything a 'good read' should be.

But this will certainly not be the last biography of one of the leading and most colourful of US planetary scientists. And one cannot help feeling that Levy was too close, and that the book has been written too soon. Perhaps by 2050 or 2100 we will see more clearly where Gene Shoemaker fits into the investigation of Armageddon asteroids, killer comets and their potential effects on life on Earth.

It is also too early to argue about whether Gene was the best US planetary scientist of the last century, or number two, three or four on the list. But his life was a fascinating example of how a happy man approaches and successfully dominates a subject he loves. No two scientists are the same, but very few suddenly start working full-time with their wives at the age of 52 . And very few, at 52, can throw off the shackles of administration, and turn, full-time, both to searching space for comets and asteroids, and to hunting the desolate ancient regions of the continents for the signatures of the destruction these impactors can inflict on our as-yet defenceless Earth.

Shoemaker by Levy is an interesting biography. But I would love to compare it with, 
say, 'Shoemaker by Carolyn', or 'Shoemaker by Eleanor Helin', or even 'Shoemaker by a dispassionate scientific historian in 2050'. David W. Hughes is in the Department of Physics and Astronomy, University of Sheffield, Sheffield S3 7RH, UK.

\section{…ㄴ..ㄴ..… The psychological toll of battle}

\section{A War of Nerves: Soldiers and Psychiatrists 1914-1994 by Ben Shephard \\ Jonathan Cape: 2000.480 pp. $£ 20$ \\ Hugh Freeman}

The limits of human endurance have been the theme of many books, plays, dramas and the visual arts, as well as providing a living laboratory for psychology researchers and scientists. The worst of these situations is warfare, as it involves not just extreme physical stress, but also an agonizing mental conflict between duty and personal survival. Although this has produced a huge literature, there has been no comprehensive overview of the phenomenon of 'shell-shock' and its associated disorders. Ben Shephard has now provided this.

It was not until 1914, with the vast numbers of combatants involved in the First World War, that the fearful effects of battle were seen to become epidemic, and no army had prepared itself for this. Within the first few weeks, soldiers unable to continue fighting were being evacuated to England in large numbers, and 'shell-shock' was the label devised by the men themselves for their condition. "Of all the things that preyed on the nerves and senses," Shephard writes, "shellfire was the worst." Trench warfare took a terrible psychological toll because it meant "powerless waiting for an impersonal death".

In the medical services, there was no

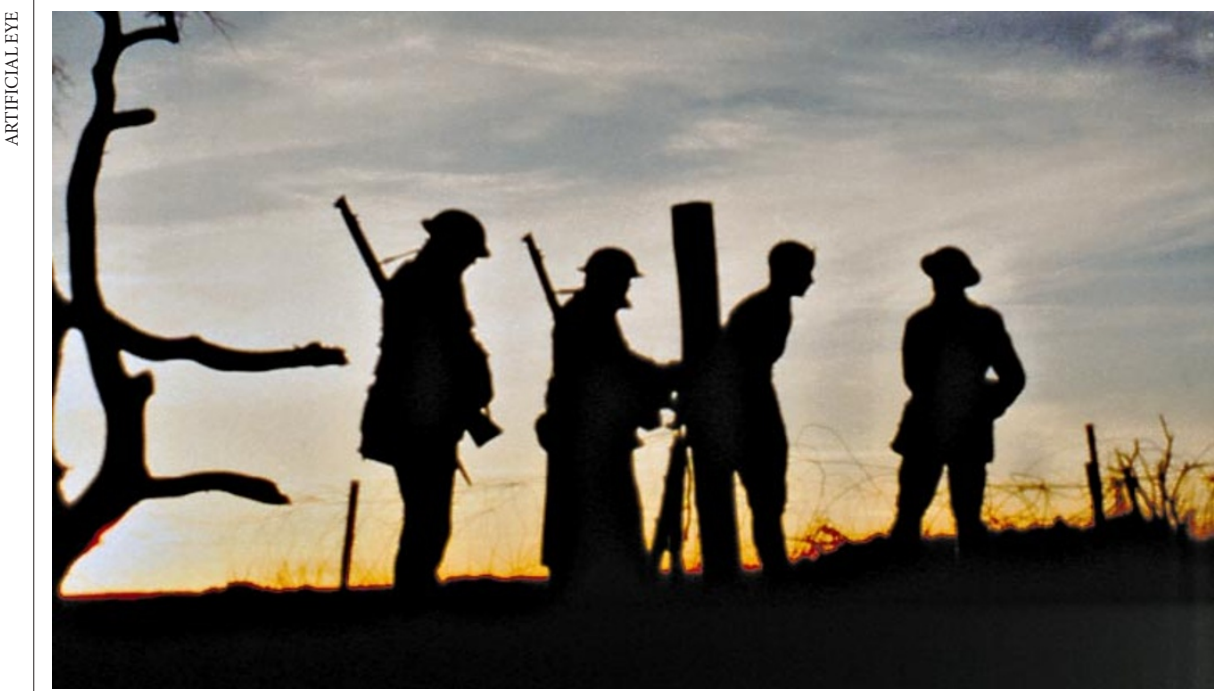

Luck of the war: a 'coward' is shot in Regeneration; others who acted the same way received pensions.

agreement on either the causes of the problem or what should be done about it. Many of the affected men showed bizarre disturbances - paralysed limbs, loss of speech or sight, or uncontrollable shaking, while others were denied sleep by terrifying nightmares. This 'hysteria' was in fact an unconscious compromise to the dilemma faced by men whose moral code would not allow them to run away but who nevertheless needed to be removed from the trenches. Sigmund Freud had described such a "conversion" of symptoms earlier, but had to admit that his exclusive concern with sexual factors was disproved by the war: fear of death had become the overwhelming influence.

The British Army turned first to neurologists, who had a selective interest in psychiatric disorders and more prestige than asylum doctors. They initially looked for microscopic damage to the brain, but found nothing; the same fruitless search was going on in France and Germany. In all these countries, neurologists used electric-shock treatment to try to dispel the hysterical disturbances. Whatever the rationale for this punitive approach, men generally preferred to return to the front line rather than face the pain of constantly increasing shocks.

A kinder therapy was being developed by British psychologists, notably Charles Myers, together with some psychologically minded doctors. Outstanding among these was W. H. R. Rivers (hero of the first book and the film of Pat Barker's Regeneration Trilogy, published by Penguin), whose psychotherapeutic technique - mainly for officers - had a Freudian basis. He accepted that experience not directly accessible to consciousness could have profound effects, and that symptoms were often the expression of mental conflict.

Regimental medical officers were torn between humane concern for their men and the need to keep units up to strength. One officer, trying to gain some respite for a depleted and exhausted battalion, was told by his army commander that the men showed "an utter want of manly spirit and courage". Yet distinguishing between men suffering genuine terror or numbing from mere cowards or malingerers was a daunting task. A shell-shocked man might be given a wound stripe and a pension, be told to pull himself together, or be shot for cowardice sometimes it seemed largely a matter of chance which of these it was. Altogether, the British Army executed 307 men, the French 700 and the German Army only 48. After 1918 , though, undue sympathy for war neurotics was widely condemned in Germany as contributing to the German defeat. It would be different next time.

But there was a virtual consensus that shell-shocked men who were evacuated far from the battle zone were unlikely ever to return to it. From this experience, the idea of 'forward psychiatry' emerged. Casualties would be dealt with as near to the front line as possible; in many cases, a few days' rest and food were effective enough. Only more serious cases were evacuated further away.

When peace came, every combatant nation had an enormous legacy of psychiatric casualties, with a corresponding burden of pensions - Britain was still paying 40,000 in 1939. Although the war had given a slight boost to the development of psychotherapy in Britain, mental hospitals largely returned to their pre-war torpor.

During the Second World War, psychiatry no longer played second fiddle to neurology - except in the Royal Air Force. Shephard says it is still almost impossible to obtain any information about the degree of psychiatric breakdown that occurred in aircrew. But even rigorous selection among these volunteers failed to pick out every vulnerable one. Meanwhile, the army had to relearn the need for forward psychiatry, finding that when the Allies were winning, psychiatric casualties (and desertions) were far fewer. Psychiatrists also played a major role in the selection of personnel, although without the approval of Winston Churchill. Germany, on the other hand, executed 15,000 men, and over 20,000 more killed or maimed themselves. Whether psychiatric breakdown in war is contagious and whether executions discourage it remain unresolved questions.

The US Army had to start from scratch in learning to deal with psychiatric casualties, which made up some $30 \%$ of total casualties when the US Army first encountered the Wehrmacht in Tunisia. Vicious fighting in the Pacific also took a heavy toll. The United States had always been generous to veterans, and ample free services were provided for both physical and psychiatric impairmentin Shephard's view, the generosity may often have prolonged the disability.

The Vietnam War was another matter. Morale was low, drug addiction rife (though 